\title{
Research on the Revolution of the Catering Industry in the Platform Economy
}

\author{
Peiyi Zhang
}

Management School Lancaster University Lancaster LA1 4YW UK

Email:Francesca5225@hotmail.com

\begin{abstract}
In the context of the information age, the platform economy has gradually become an essential tool for economic transformation along with the development of science and technology, meanwhile, the traditional catering industry is encountering the problem of performance deterioration. Therefore, it is compulsory to combine the catering industry with the online platform, leading to the development of innovative business models under the support of the platform economy, such as $\mathrm{O} 2 \mathrm{O}$ (online-offline) mode. Although the growth period of platform economy theory is less than 30 years, this paper attempts to examine the platform economy and analyse the way that the traditional catering industry realises the revolution with the help of $\mathrm{O} 2 \mathrm{O}$ mode. Through case studies of three enterprises including Ele.me, Deliveroo and Haidilao, it discovered that the revolution of the traditional catering industry is mainly reflected in the following aspects: first, the reduction of cost; second, accurate matching of information; third, the breakthrough of the time-space constraints; fourth, the improvement of employment rate. This paper explores the current development trend of the catering industry, from the perspective of the platform economy, and tries to lay the theoretical foundation for the research on the transformation of the traditional catering industry.
\end{abstract}

Keywords: Platform Economy, Catering Industry, O2O Mode

\section{INTRODUCTION}

If the industrial revolution is regarded as revolutionising around factories, the current revolution is all around platforms, namely, the application of algorithms running on massive databases in the cloud [1]. The outstanding performance of these digital platforms demonstrates that we are in the process of economic restructuring. In this process, the potential that platform companies are developing could be nearly equivalent to that of Ford, general motors and general electric in the early days. Farrel et al. [2] state that 'technological innovation is transforming economic exchange'. The online platform, ten years ago, was merely used to connecting independent sellers and buyers for trading limitedly physical goods. However, today's customers can acquire roughly any kinds of goods or service from traders though online platform at any time. It is because current platforms have the ability to mobilise the information and resources, and the power to match them effectively and efficiently [3]. The platform itself does not produce a product but can facilitate a transaction between two or more parties concerning supply and demand. The platform economy can be regarded as a large market, where people comes to trade, and the market charges booth fee, transaction fee or protection fee so that everyone is able to trade freely in this market.

The platform economy is not a brand-new term. The roles in traditional economy played by banks, securities, shopping centres and intermediary companies altogether belong to the platform economy. Accordingly, there are arising plenty of energetic and extraordinary platforms, which broadly spread into a variety of business field. Nonetheless, it is challenging to categorise these various platforms precisely. For instance, although Google and Facebook, as digital platforms, offer search engine and social media, they provide other platforms with a substructure to build as well. Like Etsy and eBay, Amazon is an online market. However, its Web Services (AMS) can be used by others as an infrastructure and implements to construct more platforms. Moreover, Airbnb and Uber utilise those newest cloud computing tools, pushing existing businesses to renovate intensely. These different platforms jointly create markers and reorganisation of work arrangements, which eventually result in the creation and capture of value [4].

Benefitting from the express advancement of network 
technology and speedy revolution of the business environment, it is much more apparent for the advantages of the online platforms, meanwhile, the disadvantages of the traditional catering industry, which spontaneously forcing the combination of the catering industry and platform economy [5]. Especially for miniature and middle-scaled restaurants with small dining environment, the restrained ability for serving consumers, utilising the online take-away platform to increase sales is their best opportunity [6]. Through years of exploitation and expansion, the food delivery market has occupied a necessary position of food and beverage industry (this phrase is synonymous with the catering industry in this article). With the help of information technology, traditional promotion tools of catering trade are able to improve the efficiency of communication with much more consumers, as well as the quality of service processing. Restaurants can provide online-to-offline services and offline-to-online services, which includes pre-booking seats, network queuing, pre-order meals, electronic membership card and online notifications of marketing campaigns. Concisely, the platform economy is a cutting-edge economic model driven by innovations of technology and business model, which is formed via resource sharing, industry integration and commercial format upgrading.

This article plans to, firstly, clarify the definition of Platform and Platform Economy. Secondly, discuss the different online platform modes generated by the combination of the platform economy and catering industry. And then summarise the characteristics of the transformation of traditional catering industry under the background of the platform economy by studying the cases of three well-known platform catering enterprises: Ele.me, Deliveroo and Haidilao.

\section{LITERATURE REVIEWS}

\subsection{Platform and Platform Economics}

The concept of 'Platform' first appeared in the research literature about new product development [7]. Owing to the differences in research fields and perspectives, scholars have given different definitions of platforms. Baldwin and Woodard [8] believe that the platform is a stable component in the system, which can constrain the connection of others, therefore, supporting the diversity and evolvability of the system. In the software industry, platforms provide the core functions shared by other modules and provide the interface for additional modules to interoperate with the platform [9]. Industry economists represented by Tirole [10] define the 'Platform' as a company or organisation who can provide transaction intermediaries via two or more parties.

With the in-depth research on platforms, platforms have rapidly expanded and extended in business and industry, forming specific business models and enterprise competition strategies, so that platform economics has also been born. Despite rich and emerging literature, there is no unified conclusion on the theory of the platform economy in the academic world. From the perspective of existing academic research, the theory of platform economy is primarily related to two-sided market theory. Armstrong [11] focus on the network externality: two groups of participants traded through a platform or intermediary, and the profit of one group of participants from the platform depended on the number of participants in the other group. Rochet and Tirole [12] proposed the principle that the price structure is not neutral, which is mainly worked in the case of transactions between bilateral users. It emphasises that the platform charges bilateral users for transactions, and the transaction volume can be adjusted by charging different prices to bilateral users.

Overall, the platform economy is a new form of industrial organisation, which based on digital technology, data-driven and platform support. It aims to improve efficiency and reduce cost by means of changing the business process, industrial chain integration and multibusiness combination. Platform economic connects stakeholders based on the connection between real and virtual space-time, which shapes a new economic ecosystem. Trough platform economic activities, to realise information aggregation and transaction centralisation, stakeholders can benefit from the platform. Undoubtedly, it is able to encourage the incorporation of production factors, enhance the efficiency of resource allocation, reconstruct the value chain of the traditional industry, and accelerate the revolution of business model.

\subsection{Transformation of the Food and Beverage Industry}

According to Luo's research [13], the traditional catering industry mainly faces with three problems: a) blind expansion of business scale; b) the backwardness of the empirical management mode; c) lack of standardised technology and competitive brands. As a traditional production industry, the catering industry has been developing rapidly. However, the demand of the market has led to the blind expansion of catering enterprises. This causes the enterprise to fall into adverse competition, which has weakened its competitiveness and the capacity of development. Besides, most catering companies do not have a powerful management system. Operators tend to rely on their own experience to manage the business. Therefore, it is badly needed for managers to innovate management mode, creating new development direction for the catering industry. Finally, without standards and technical guidance, traditional catering companies are not mature enough in the level of processed food. It is relatively difficult to form an industrial scale in the food and beverage industry, leading to a lack of competitive brands. 
As stated before, the platform economy accelerates the revolution of business model, as well as supporting the construction of new platform business models. Instead, the development of advanced platform mode also promotes the development of the platform economy. With the deterioration of the performance of the catering industry and the rapid enlargement of the online platform, merchants gradually pay attention to the $\mathrm{O} 2 \mathrm{O}$ (online-tooffline) model in the catering industry. Its starting point is attracting more consumers through the network to finish meal ordering and delivery service. More importantly, through online transactions, it makes consumers and business operators enjoy convenient services and also achieves mutual satisfaction. The founders of Trialpay first proposed the concept of $\mathrm{O} 2 \mathrm{O}$ in 2010 [5]. It is characterised by multi-channel; explicitly, enterprises provide products or services to consumers through a combination of offline and online channels. Yaofeng [14] and Dongzhen [15] define this model as attracting consumers to pay online and then eventually receive services or products offline. Another aspect of $\mathrm{O} 2 \mathrm{O}$, Guizhen [16] asserts, is that merchants use marketing strategies to get consumers to buy online services and products after experiencing their offline services. Bo [17] concludes further that the $\mathrm{O} 2 \mathrm{O}$ model comprises 'online to offline, offline to online, offline to online and then to offline, online to offline and then to online'.

Based on the finding of Yong et al. [5], O2O systems in the catering industry can be divided into three diverse categories: the first type is Group-buying O2O Mode. It uses online incentives to entice customers to consume offline, such as offering discount packages or coupons on the platform, so that customers can have a meal in the physical store at a more favourable price. When customers go to a store for consumption after purchased a group purchase order, they frequently consume other dishes. The overall sales and gross profit of the store, therefore, would be raised. The second mode is the Takeout Platform. It can be further subdivided into two forms. One is the Aggregators, which emerged in 2001 as the most traditional platform of take-out delivery, in which the restaurants distributes its goods and services [18]. The other is New Delivery appeared in 2013. Under this form, platforms establish its own logistics network to provide delivery services for the catering industry without delivery staff. The last is the Enterprises One-stop O2O Mode. Commonly, enterprises in this model are chain restaurants who master standard production processes, and they need to complete all processes such as food procurement and production, system information processing, and independent distribution. Since chain restaurants tend to have sufficient funds to develop systems and online APPs independently, they can make appropriate use of $\mathrm{O} 2 \mathrm{O}$ to benefit multiple branches and reduce marginal costs.

\section{CASE ANALYSIS AND DISCUSSION}

\subsection{The Case of Ele.me}

Ele.me is a leading food delivery brand in China, which was founded in 2009. After six years of development, in 2014, Ele.me has spread to more than 200 cities in China, with 10 million users and 180,000 franchised restaurants, whose daily orders have exceeded 1 million. In April 2016, Alibaba Group invested \$1.25 billion in Ele.me to help Ele.me attract more customers and make further improvement. With the development of Ele.me, it has promoted the digitalisation process of the whole Chinese catering industry and provided a unified marketing management method.

The core competitive advantage of Ele.me is the invention of two internal software, Napos and Walle, which significantly reduced operating costs and human resource management costs [19]. Napos focuses on the backstage management of restaurants. Restaurants can efficiently process food delivery and online payment via Napos. It can be operated to manage the day-to-day background management of the restaurant as well, such as kitchen order management. Whereas Walle is targeting the internal staff of Ele.me. As a CRM (Customer Relationship Management) software, Ele.me has the capacity to record the performance and training of employees, additionally displaying their daily performance on a public platform to improve work efficiency.

Apart from that, the "Hummingbird" distribution system independently developed by Ele.me can automatically locate the location of each deliverer and realise real-time tracking of orders by customers. This system breaks the constraints of time and space. Through the supervision of food delivery, customers can improve their trust in the company. In addition, Ele.me has established communication channels with customers to grasp their demands timely and increase their goodwill and dependence [20]. Similarly, in order to maintain a good relationship with customers, Ele.me has set up an evaluation system for each restaurant on its platform, where consumers can evaluate food quality, delivery speed and service quality. These evaluations help Ele.me to find out its inadequacies in a timelier manner and ensure good consumption experience for consumers.

\subsection{The Case of Deliveroo}

Deliveroo is founded in 2013 by two American businessmen, which head office is based in London, UK. At present, the company's business throughout the Netherlands, France, Belgium, Spain, Italy, Australia, Singapore and other countries, which was valued at \$2 billion in merely five years [21]. Deliveroo focuses on providing high-end food delivery services using the Uber model, promising to deliver meals within 32 minutes. It 
charges $£ 2.50$ for orders over $£ 15$ or charges $£ 4.50$ if the order price is less than $£ 15$. Similar to Uber, Deliveroo is seen as 'Uber for food delivery', although it also competes with Uber's UberEats. In Deliveroo's own words, it connects 'hundreds of chain restaurants and many high-quality independent restaurants' with 'an excellent team of drivers' [22]. It is worth noting that Deliveroo defines drivers as "autonomously independent contractors", stating they only link the restaurant and the driver, rather than paying the wage to hire anyone.

In addition to high-end food delivery, Deliveroo has launched 'Deliveroo Editions', a shared kitchen that provides partner restaurants with customised kitchen workshops, delivery services and marketing support. Deliveroo Editions generates most of its revenues from partner restaurant rentals and a cut of orders. It has accumulated high-end user data from a large number of orders, built its own database, and then analysed the service gap areas where customers have high demand but few food choices. Subsequently, Deliveroo can manufacture kitchen sites for related brand restaurants, providing take-out delivery. Deliveroo provides shared kitchen workshops for partner restaurants to reduce the risk of setting up in high-priced communities, expand the restaurant's coverage, increase the restaurant's supply capacity, and provide more job opportunities in the area. It helps the restaurant focus more on the food itself. While this new format is still being piloted, it may be the next step in the development of the platform economy and could further transform the catering industry.

\subsection{The case of Haidilao}

Haidilao Catering Co. LTD is a large cross-border private catering enterprise which mainly focuses on Sichuan style hot pot and integrates different characteristics of the hot pot into one. Haidilao has more than four large modern logistics foundations and a raw material production base [23]. As the most well-known catering chain enterprise in China, it is one of the earliest catering chain enterprises adopting O2O marketing. Strengthening customer relationship management (CRM) has always been the target of Haidilao, especially in the era of Mobile Internet. Given that the success of Haidilao is mainly attributed to their comprehensive quality service offline, it makes more use of the word-of-mouth publicity of various online review platforms. Haidilao promotes the transformation of users to offline so as to realise the positive cycle of online brand communication and offline sales promotion [24]. For ensuring the accurate communication of information, correspondingly, Haidilao has accounts on varied social media platforms, which are used for promotion and public relations respectively.

Haidilao has had online food ordering and delivery services since early 2011. In 2012, Haidilao's take-out platform opened 24 hours a day as the same as its offline stores, providing take-out services for users who could not go to the store for consumption. With the development of wireless mobile phone and smartphone, Haidilao also launched a mobile application in addition to the platform website, therefore successfully reached a one-stop service. Along with supporting multiple people to order online simultaneously, Haidilao's system is able to intelligently recommend and even customise dishes that might match customers' tastes, through the analysis of customers' ordering records in its platform database [25].

\section{CONCLUSIONS}

Combined with literature review, the platform business model of these three cases can be summarised: both of Ele.me and Deliveroo belong to the $\mathrm{O} 2 \mathrm{O}$ mode of New Delivery because they have their own logistics network and offer delivery services for the cooperative enterprise. Unlike Ele.me and Deliveroo, Haidilao adopts the Enterprises One-stop O2O Mode, as it masters standard production processes and has the ability to complete all processes independently. Nevertheless, there are two visible differences between Ele.me and Deliveroo: first, the delivery services are contracted to other agents, rather than making the deliverers become independent contractors; second, Deliveroo focuses on high-end dining, on the contrary, Ele.me has a broader range of partners.

When it comes to the most apparent revolution characteristics of the catering industry, the first is the reduction of costs: as these three companies administer orders through the online platform, the labour cost of receiving and distributing orders can be reduced; The development of internal management software saves operating costs; Through actively using social media platforms, marketing costs would be diminished.

Secondly, information can be accurately matched: constructing independent database, sharing information with consumers in real-time, promoting on various social platforms are all aimed at guarantee accurate matching of information among customers, restaurants and platforms, so as to expand audience groups and improve service experience.

The third feature is the breaking of the constraints of time and space: it is embodied in the realisation of realtime tracking of orders, the launch of 24-hour take-out delivery services, and the establishment of Shared kitchens to expand the coverage of restaurants.

Lastly, the improvement of employment rate: due to the fact that take-away platforms require a large number of riders to deliver goods and services, and the newly built Shared kitchen needs staff to operate, besides the 24-hour business pattern involves numerous staff to work in rotation, it also provides employment opportunities for more people. 


\section{CONCLUDING REMARK}

In conclusion, platform economics leave room for innovation business structure to evolve. As the most typical business model in the platform economy, $\mathrm{O} 2 \mathrm{O}$ platform mode further accelerates the transformation of the catering industry. Through the case studies, it is concluded that the revolution of the catering industry is mainly reflected in four aspects: a) reduction of cost; b) accurate matching of information; c) breakthrough in the constraints of time and space; d) improvement of employment rate. The following figure shows the conclusion of this article visually:

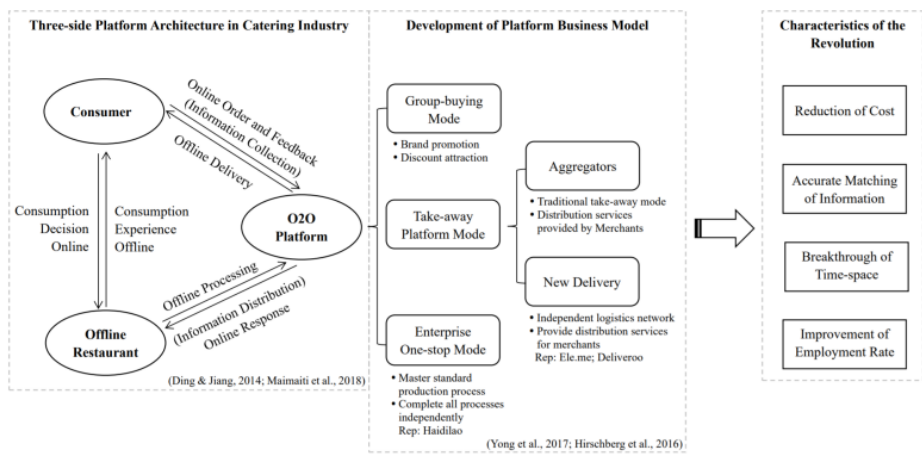

Figure 1. The Development and Reform of the Catering Industry Driven by Platform Economy. (Image Credit: Arranged and drawn by the author)

\subsection{Research Limitations}

Strictly speaking, the characteristics of the revolution concluded in this paper only refer to the several factors reflected in the transformation. These factors, the performance of economic improvement, are driving revolution. If we want to analyse the reform of catering industry comprehensively and accurately, much more detailed empirical researches are required. Beyond that, research results on the application of the platform economy in the industrial economy are relatively rare, and existing relevant studies are all theoretical and descriptive definitions, lacking empirical studies. Moreover, the research on the combination of platform economic study and other fields is not systematic, indepth and disordered. However, in-depth reviews on the transformation of traditional industries by platform economy are even more scarce. Since there are few empirical data on the combination of the catering industry and platform economy, it is of great difficulty to verify the accuracy of the figures in the literature. Therefore, there is no generally accepted theory about the impact of these different platforms on the overall economy.

\subsection{Potential problems in the platform economy}

Although the $\mathrm{O} 2 \mathrm{O}$ food industry has apparent advantages, it also brings some problems. As a third party, the $\mathrm{O} 2 \mathrm{O}$ food platform integrates all information, which leads to problems such as decentralised responsibility, weak supervision and lack of service standards [27]. First of all, the personal safety of employees is not easily guaranteed. Deliveries are usually made by bike or motorcycle, and the risk of injury in an accident is relatively high. However, health insurance, accident insurance and third-party liability insurance are all included in the responsibility of 'independent contractors' (the deliveryman). In this case, some riders tend to cut these costs and take their risks. Furthermore, the delivery platform has strict requirements on the delivery time, which makes it more difficult for riders to pay attention to safety in the case of fast driving. Another problem is the impact on the ecological environment. Take-out food is usually packaged in plastic, and improperly disposing of the chemicals in the waste can lead to land and sea pollution, contributing to climate change. The last issue that is easy to notice is the disclosure of personal privacy, in the context of big data, information about food and eating habits is also given commercial and managerial value. There is no doubt that restaurateurs want more individual data to strengthen their marketing tools. If some digital platforms lack oversight, private data could be leaked or bought and sold [28].

\section{REFERENCES}

[1] Kenney, M., \& Zysman, J., 2015, Choosing a future in the platform economy: the implications and consequences of digital platforms[C]. In Kauffman Foundation New Entrepreneurial Growth Conference, vol. 156160.

[2] Farrell, D., Greig, F., \& Hamoudi, A., 2018, The online platform economy in 2018: Drivers, workers, sellers, and lessors[J]. JPMorgan Chase Institute.

[3] Roson, R., 2005, Auctions in a two-sided network: The market for meal voucher services[J], Networks and Spatial Economics, vol. 5, pp. 339-350.

[4] Kenney, M., \& Zysman, J., 2016, The rise of the platform economy[J]. Issues in science and technology, 32(3), 61. 
[5] Yong, X., Yingxin P., \& Ni, Z., 2017, Analyse O2O Mode in Catering Industry from the Perspective of Supply Chain[J]. International Journal of Business and Industrial Marketing, Vol. 2, No. 6, pp. 62-67.

[6] Xuecheng, W. \& Zongyi Y., 2017, Internet platform business model renovate catering industries: Evidence from 3199 catering enterprises on Dianping.com in Haidian district[C]. 2017 4th International Conference on Industrial Economics System and Industrial Security Engineering (IEIS), pp.1-5.

[7] Wheelwright, C. \& Clark, B., 1992, Creating Project Plans to Focus Product Development [J]. Harvard Business Review, 70(2).

[8] Baldwin, Y., \& Woodard, J., 2008, The architecture of platforms: a unified view[J]. Harvard Business School Finance Working Paper.

[9] Tiwana, A., Konsynski, B., \& Bush, A., 2010, Research commentary: platform evolution: coevolution of platform architecture, governance, and environmental dynamics[J]. Information Systems Research, 1(4): 675-687.

[10] Rochet, C., \& Tirole, J., 2003, Platform competition in two-sided markets[J]. Journal of the European Economic Association, 1(4): 990-1029.

[11] Armstrong, M., \& Wright, J., 2007, Two-sided markets, competitive bottlenecks and exclusive contracts[J]. Economic Theory, vol. 32, pp. 353-380.

[12] Rochet, J, \& Tirole, J., 2006, Two-sided markets; A progress report[J]. Rand journal of Economics, 37 (3), 645-667.

[13] Luo, Y., 2018, Innovative Research on Catering Management[J].

[14] Yaofeng, H., \& Xiaoxiong Z., 2012, Analysis of security system in $\mathrm{O} 2 \mathrm{O}$ of electronic commerce[J]. Information Security and Communications Privacy, 2012(11): 121-123.

[15] Dongzhen, L., \& Wanfeng, D., 2013, Research on the organisational model based on $\mathrm{O} 2 \mathrm{O}$ in ecommerce[J]. Electronics world, 000(004):10-11.

[16] Guizhen, H., 2013, Study on the application of O2O mode in Chinese catering enterprises[J]. China Business \& Trade, 2013(7): 130-131.

[17] Bo, Z., 2013, O2O-Business revolution in the era of mobile Internet[J]. China Machine Press. Beijing.

[18] Hirschberg, C., Rajko, A., Schumacher, T., \& Wrulich, M., 2016, The changing market for food delivery[J]. Mckinsey and Co.

[19] Ye, Y., 2015, Online to Offline Food Delivery
Situation and Challenges in China. Case company Ele.me[J].

[20] Yaping, T., \& Tianyu, Z., 2017, Successful Case Analysis of $\mathrm{O} 2 \mathrm{O}$ Catering Industry -- Taking 'Ele.me' as an example[J]. Modern Commerce 2017(32), 39-40.

[21] Belleri, C., 2020, Deliveroo: improving a service making IT 24 hours[J]. EAE.

[22] Woodcock, J., 2020, The algorithmic Panopticon at Deliveroo: Measurement, precarity, and the illusion of control[J]. Forthcoming in Ephemera.

[23] Liang, M., Wang, M., \& Xu, S., 2016, WeChat Marketing of Catering Industry from Consumers' Perspective-Taking "HaiDiLao" and "Little Sheep" as Examples[J]. Journal of Service Science and Management, 9(03), 255.

[24] Bing, Z., 2014, Application analysis of o2o model in catering Industry -- taking Haidilao as an example[J]. Journal of Henan Commercial College, 000(005), 54-57.

[25] Yajuan, S., 2015, Haidilao how to use the Internet to 'adjust the taste' [J]. Successful Marketing 2015(07), 67-70.

[26] Ding, H., \& Jiang, L., 2014, Business Model and Mobile Marketing Strategy of Online to Offline: An Exploratory Study[J]. Journal of Logistics, Informatics and Service Science, 1(2): 1-9.

[27] Maimaiti, M., Zhao, X., Jia, M., Ru, Y., \& Zhu, S., 2018, How we eat determines what we become: opportunities and challenges brought by food delivery industry in a changing world in China[J]. European journal of clinical nutrition, 72(9), 12821286.

[28] Lewis, T., 2018, Digital food: from paddock to platform. Communication Research and Practice[J], 4(3), 212-228. 